\title{
Practitioners or Academics - Do Students Care?
}

\author{
Kurt Schobel \\ Royal Military College of Canada
}

\begin{abstract}
For more than two decades there has been discussion around the notion of students as customers and whether universities need to consider student demands. In business schools where the concept of customer relationship management is often discussed, this notion is even more apparent. With this in mind, this study will look at the types of professors that students expect in a business school. The Association for the Advancement of Collegiate Schools of Business (AACSB) recognizes qualified faculty as having either a theoretical academic formation ( $\mathrm{PhD}$ or Doctorate) or a more practical formation (Accountants and Lawyers). The purpose of this study is to identify whether students who view themselves as customers have a preference.
\end{abstract}

Keywords: Business, education, faculty qualification, student-customer, accreditation 